\title{
Synthesis of Decaarylanthracene with Nine Different Substituents
}

\author{
Takashi Asako, Shin Suzuki, Shuhei Tanaka, Eisuke Ota, and Junichiro Yamaguchi* \\ Department of Applied Chemistry, Waseda University, 3-4-1, Ohkubo, Shinjuku, Tokyo 169-8555, Japan \\ Supporting Information Placeholder
}

\begin{abstract}
A synthesis of decaarylanthracene with nine different substituents has been accomplished by a coupling/ring-transformation strategy. The oxidation of tetraarylthiophenes with four different substituents to the corresponding thiophene $S$-oxides, and a $[4+2]$ cycloaddition with a double benzyne precursor afforded a multiply arylated naphthalene derivative. Subsequently, the naphthalene derivative was converted into a naphthalyne, and then a $[4+2]$ cycloaddition of another thiophene $S$-oxide provided decaarylanthracenes with nine different aryl groups.
\end{abstract}

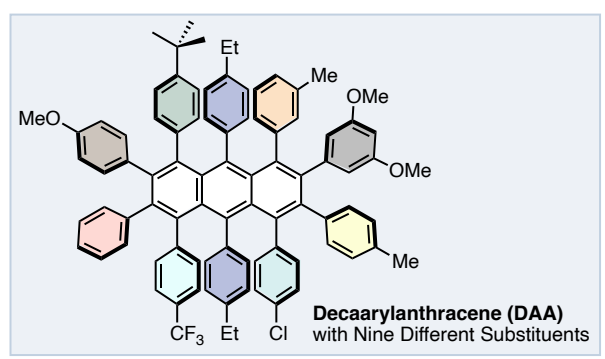

\section{- INTRODUCTION}

Acenes are linearly fused aromatic rings that are classified as polycyclic aromatic hydrocarbons (PAHs). These highly conjugated structures have excellent optical and organic electronic properties, and have been well-studied for two decades ${ }^{1}$ Particularly, acenes with multiple aromatic rings are organic electronic materials for everyday societal use (Figure 1). For example, oligoanthracene, which have three anthracenes connected to each other, is utilized as an organic field-effect transistor (OFET). ${ }^{2}$ Additionally, dinaphthylanthracene, which has two naphthalene groups bonded to an anthracene unit, is well-known as an organic light-emitting diode (OLED). ${ }^{3}$ Rubrene, which has four benzene substituents on a central tetracene core, is also used in OLEDs, OFETs, and organic semiconductors. ${ }^{4}$ Another OLED material is known: fused anthracene, in which eight of the hydrogens on anthracene are substituted with aryl groups. ${ }^{5}$ Therefore, the development of efficient methods to introduce multiple aryl groups onto acenes is necessary, and in turn gives us the opportunity to create innovative functional molecules. ${ }^{6}$

Specifically, anthracene has been synthesized from dihydroanthracene using oxidative methods, and from anthraquinones using reductive methods, as well as by retrocyclization. ${ }^{7}$ However, these methods are limited in the number of substituents that can be introduced. Another known method is the synthesis of anthracene derivatives by the cycloaddition of benzynes. For example, Pascal and co-workers have successfully synthesized decaphenylanthracene (DPA) using a [4+2] cycloaddition of benzynes (Figure $2 \mathrm{~A}){ }^{8}$ This synthesis involved the cycloaddition of a substituted benzyne, which was generated from tetraphenylanthranilic acid, with hexaphenylisobenzofuran. This pioneering synthetic strategy can be applied to other polyphenylacenes as well. ${ }^{9}$ However, the substituents introduced in this manner are limited to only phenyl groups, and there are no examples of decaarylanthracenes that have different aromatic substituents.

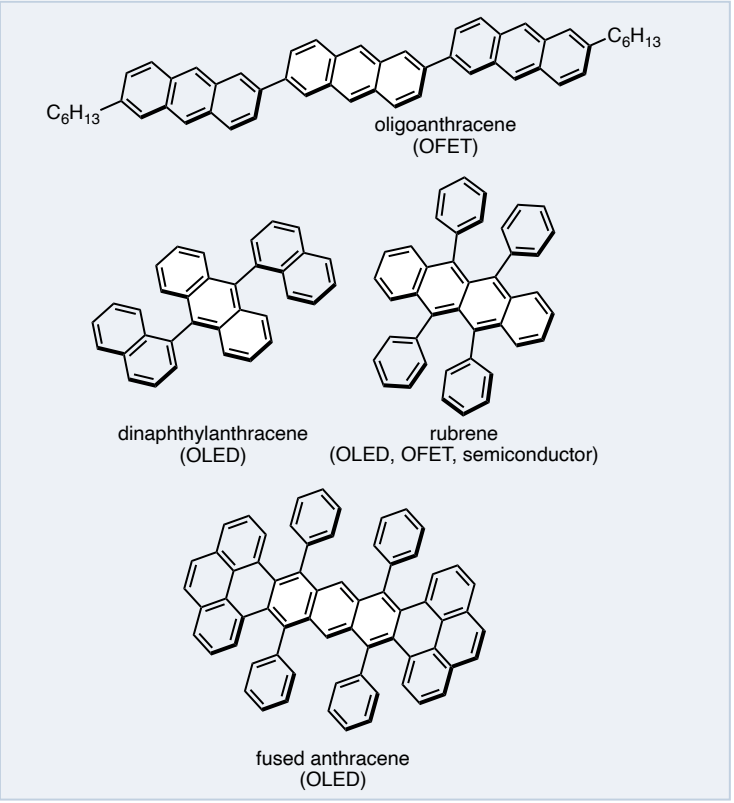

Figure 1. Multiply arylated acenes in organic materials.

Meanwhile, in 2015, we developed a coupling/ring transformation strategy and applied it to the first synthesis of hexaarylbenzenes (HABs) with five and six different aryl groups (Figure 2A).10 Our $\mathrm{HAB}$ synthesis commenced with cross-coupling reactions (involving $\mathrm{C}-\mathrm{H}$ arylations) of 3-methoxythiophene to give tetraarylthiophenes with four different aryl groups (Figure 2B). Oxidation of the thiophenes, then [4+2] cycloaddition/desulfonation of the resulting tetraarylthiophene $\mathcal{S}$-oxides with diarylalkynes, afforded the HABs. This demonstrated a net ring transformation from a thiophene to a benzene, and this general strategy has been applicable for the synthesis of multi-arylated azines, heteroles, and acenes (Figure 2C). As such, we have achieved the synthesis of pentaarylpyridine (PAP) ${ }^{11 a}$ hexaarylindole (HAI) ${ }^{11 \mathrm{c}}$ hexaarylisoquino 

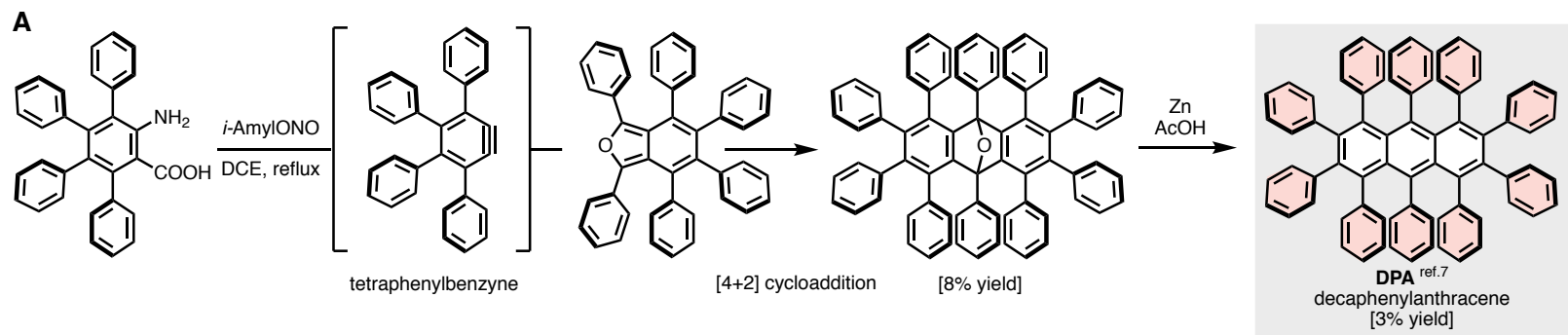

B
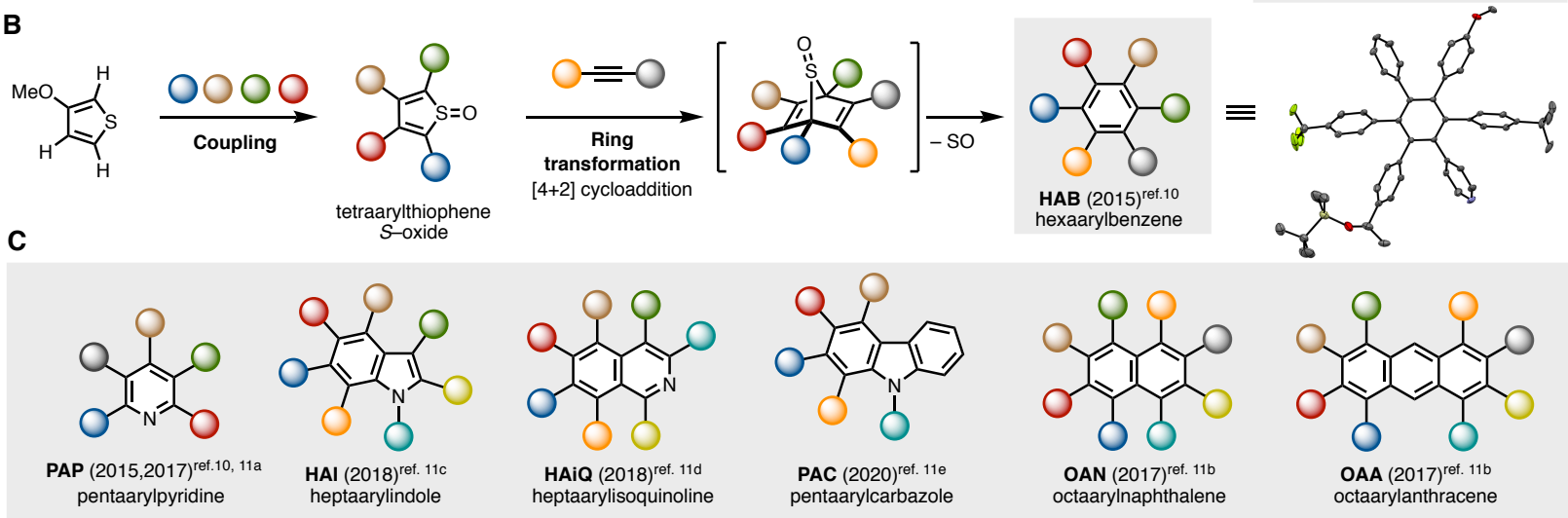

D

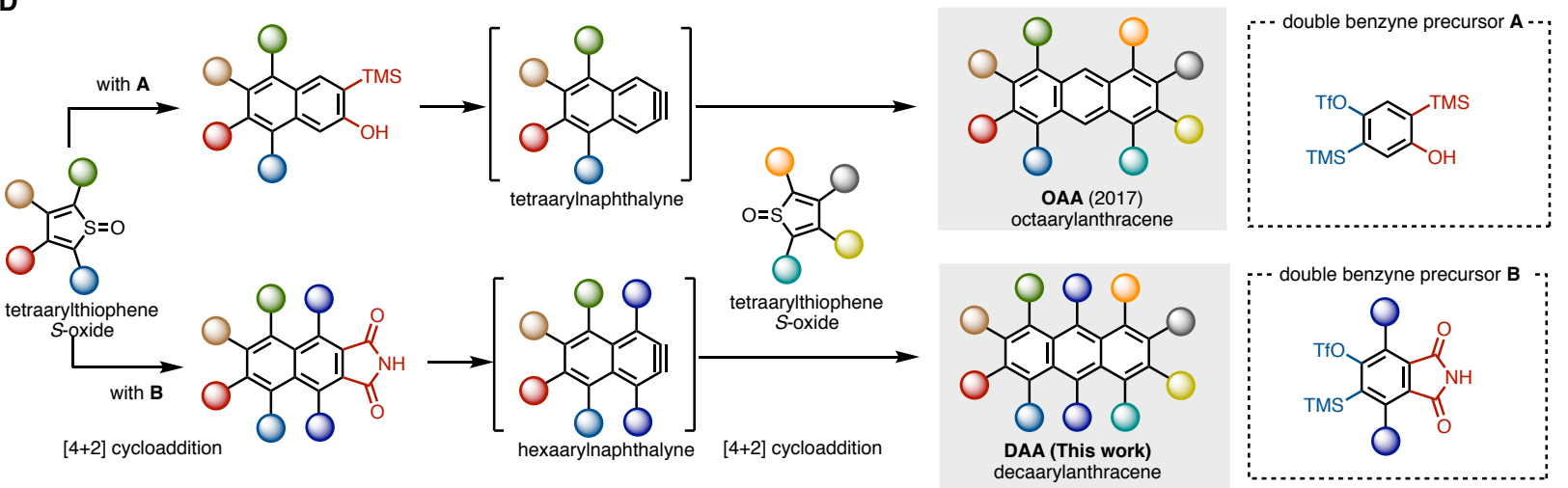

Figure 2. (A) A pioneering synthesis of decaphenylanthracene (DPA) by Pascal and co-workers. (B) A synthesis of hexaarylbenzenes through a coupling/ring transformation strategy. (C) Syntheses of multi-arylated heteroarenes, heteroles and acenes by using the coupling/ring transformation strategy. (D) Previously synthesized octaarylanthracene (OAA), and synthesis of decaarylanthracene (DAA; this work).

line (HAiQ), ${ }^{11 \mathrm{~d}}$ and pentaarylcarbazole (PAC), ${ }^{11 \mathrm{e}}$ as well as octaarylnaphthalene $(\mathrm{OAN})$ and octaarylanthracene (OAA). ${ }^{11 \mathrm{~b}}$ In the synthesis of $\mathrm{OAA},{ }^{11 \mathrm{~b}}$ the target molecule was divided into three units: two tetraarylthiophene $S$-oxides and a double benzyne precursor A (Figure 2D) ${ }^{5,12}$ First, the tetraarylthiophene $\mathcal{S}$-oxide was reacted with a benzyne (which was generated from a double benzyne precursor $\mathbf{A}$ with an appropriate base) via $[4+2]$ cycloaddition to afford the desired adduct. Thereafter, generation of a tetraarylnaphthalyne in the presence of another tetraarylthiophene $S$-oxide produced OAA through another [4+2] cycloaddition. Although we accomplished OAA by using a coupling/ring transformation strategy, the synthesis of decaarylanthracene (DAA), which would be a highly crowded assembly of 10 aryl groups onto the anthracene core, was not achievable with the same route. To realize the synthesis of DAA, a double benzyne precursor B, with two additional aryl groups on the benzene core, was designed. Precursor $\mathbf{B}$ has an imide group and an $o$-trimethylsilylaryl triflate, which enables the sequential generation of benzyne intermediates under different conditions. Herein, we report the first synthesis of DAA us- ing double benzyne precursor $\mathbf{B}$ and hexaarylnaphthalyne as key units.

\section{- RESULTS AND DISCUSSION}

\section{Synthesis of a Double Benzyne Precursor.}

To synthesize precursor $\mathbf{B}$, which is in itself a highly substituted benzene core, $\mathrm{C}-\mathrm{H}$ arylation and [4+2] cycloaddition of 3methoxythiophene (1) were envisaged to be effective tools. The synthesis of precursor B commenced with $\mathrm{C}-\mathrm{H}$ arylations of 3methoxythiophene with 4-iodoethylbenzene in the presence of catalytic $\mathrm{PdCl}_{2} /$ bipy and $\mathrm{Ag}_{2} \mathrm{CO}_{3}$ to provide 2,5-diaryl-3methoxythiophene 2 in $66 \%$ yield (Scheme 1). ${ }^{13}$ After C4bromination of thiophene 2 , the resulting product was oxidized to the corresponding thiophene $\mathcal{S}$-oxide 3 to enhance the reactivity of thiophene as a diene. A subsequent [4+2] cycloaddition with dimethyl acetylenedicarboxylate provided the corresponding benzene 4 in moderate yield. In the presence of aqueous $\mathrm{HBr}$, demethylation of the methoxy group and hydrolysis of the ester proceeded 
smoothly. After acid anhydride formation, phthalimide $\mathbf{5}$ was formed in $90 \%$ yield (over three steps). Finally, the bromophenol moiety of $\mathbf{5}$ was readily converted to $\boldsymbol{o}$-trimethylsilylaryl triflate by a three-step sequence (silylation, lithiation, retro-Brook rearrange- ment followed by triflation) to afford double benzyne precursor 6 (as the equivalent unit of double benzyne precursor B in Figure 2D).

Scheme 1. Synthesis of a double benzyne precursor.
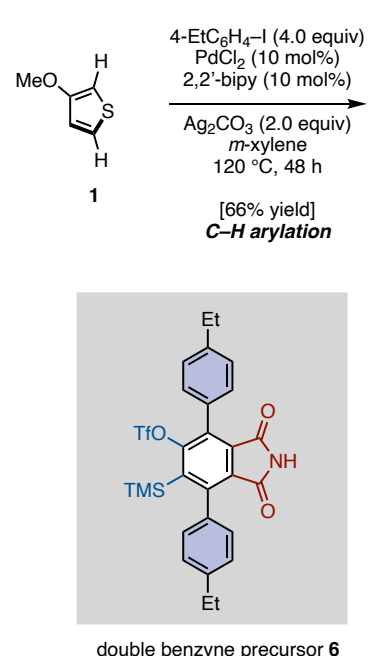

\section{[4+2] Cycloaddition Between the Double Benzyne Precursor and Tetraarylthiophene $S$-Oxide.}

With precursor 6 in hand, the synthesis of DAA was attempted by a $[4+2]$ cycloaddition with tetraarylthiophene $S$-oxide 7 a (Scheme 2A). 7a was readily prepared from 3-methoxythiophene (1) using our previously reported method in seven steps. ${ }^{11 \mathrm{~b}}$ Initially, the [4+2] cycloaddition of 6 with $7 \mathbf{a}$ under fluoride conditions to generate benzyne was examined. ${ }^{14}$ When tetrabutylammonium fluoride (TBAF), which is used for generating benzyne from $o$ trimethylsilylaryl triflate, was applied, $[4+2]$ cycloadduct 8 was not detected. Instead of the desired product 8, unprecedented 8membered ring 9 and 5,5-fused ring system 10 were formed as primary products of the reaction (Scheme $2 \mathrm{~B}$ ). Treatment with CsF using a $\mathrm{CH}_{3} \mathrm{CN} / \mathrm{DCE}$ solvent mixture only caused side reactions as well. However, when the reaction was run in DCE and toluene, 8 was detected. Tetrabutylammonium difluorotriphenylsilicate (TBAT), which is a soluble fluoride source in toluene, showed no positive effect on the yield of $\mathbf{8}$. Other inorganic fluoride sources such as $\mathrm{KF}$ and $\mathrm{NH}_{4} \mathrm{~F}$ gave no reaction. Finally, when the reaction was scaled up using CsF in toluene, in addition to the desired 6membered ring 8 (6\% yield), the undesired 8 -membered products 9 and 5,5-membered ring systems 10 were also isolated in 22\% yield and $9 \%$ yield, respectively. Although a rigorous screening of reaction conditions (solvent, temperature, concentration and stoichiometry) was conducted, the yield of $\mathbf{8}$ unfortunately could not be improved.

Next, to determine the structure of $[4+2]$ product 8 , the imide moiety was derivatized. Treatment of $\mathbf{8}$ with methyl iodide in the presence of $\mathrm{K}_{2} \mathrm{CO}_{3}$ provided $\mathrm{N}$-methylated imide Me-8 in $73 \%$ yield. Me-8 was crystallized from $\mathrm{CHCl}_{3} /$ pentane solution and characterized by X-ray crystallographic analysis. The X-ray crystal structure of Me-8 showed that the naphthalene skeleton is largely
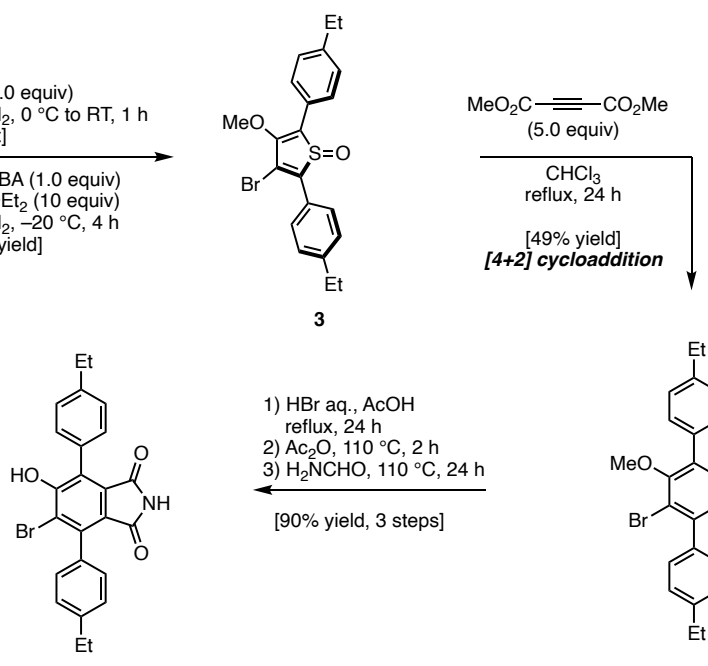

1) $\mathrm{HBr}$ aq., $\mathrm{AcOH}$

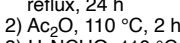

2) $\mathrm{Ac}_{2} \mathrm{O}, 110^{\circ} \mathrm{C}, 2 \mathrm{~h}$

[90\% yield, 3 steps]<smiles>[C-]OC(=O)c1c(Br)c(-c2ccc(CC)cc2)c(-c2ccccc2)c(Br)c1-c1ccc(CC)cc1</smiles>

(c)

distorted, and that the steric repulsion forces the surrounding aryl groups to avoid each other by being out of plane with respect to the naphthalene core. Additionally, from the mixture of $\mathbf{9}$, isomer 9a was isolated and $N$-methylated to give Me-9a; from the mixture of 10 , isomer $10 \mathrm{~b}$ was isolated and derivatized by demethylation, TBS protection and $N$-methylation to give TBSMe-10b. Me-9a and TBSMe-10b were crystallized from $\mathrm{CHCl}_{3} /$ pentane or 1,2dichloroethane/hexane solution and characterized by X-ray crystallographic analysis to reveal their unexpected structures.

Based on the structures of Me-9a and TBSMe-10b, two plausible reaction mechanisms are shown in Scheme $2 \mathrm{C}$. These unexpected reactions could be initiated by nucleophilic addition of $7 \mathbf{a}$ to the sterically hindered aryne formed from 6 . When the resulting carbanion attacks the $\mathrm{C} 2$ position of thiophene, a 5,5-fused ring system 10 would be formed (red arrow). On the other hand, addition of the carbanion to the sulfur atom would provide 8-membered ring 9 via carbon-sulfur bond cleavage (blue arrow). Regarding the formation of the 8-membered ring, the reaction with cyclic sulfilimines/sulfoxides and arynes afforded thiazocine/oxathiocine derivatives in a similar fashion by Hosoya, Yoshida and coworkers. ${ }^{15}$ Since these unexpected products were not observed in the reaction with thiophene $\mathcal{S}$-oxide 3 and double benzyne precursor $\mathbf{A}$ in our previous report, ${ }^{11 \mathrm{~b}}$ the steric hindrance on the periphery of the aryne appears to cause the preference for nucleophilic addition over [4+2] cycloaddition. The solvent effect (the difference between toluene and other solvents) in this reaction might be explained as follows. When using polar solvents, nucleophilic addition would be preferred due to stabilization of the ionic intermediate, and therefore the 5,5-fused ring system 10 and the 8-membered ring 9 would predominate. On the other hand, when a nonpolar solvent is used, 6-membered ring $\mathbf{8}$ formation proceeds in a slightly preferential manner. 
Scheme 2. (A) [4+2] cycloaddition of a double benzyne precursor and tetraarylthiophene $\mathcal{S}$-oxide. (B) Structural determination of the side products 9 and 10. (C) Plausible reaction mechanisms for the formation of the 5,5-fused ring system and the 8-membered ring. In the ORTEP drawing of Me8, Me-9a and TBSMe-10a, hydrogen atoms are omitted for clarity and thermal ellipsoids are drawn at $50 \%$ probabilities.

A

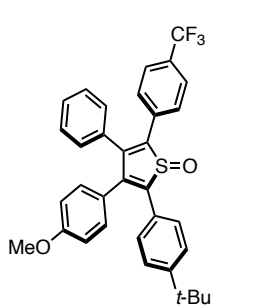

$7 a(2.0$ equiv)

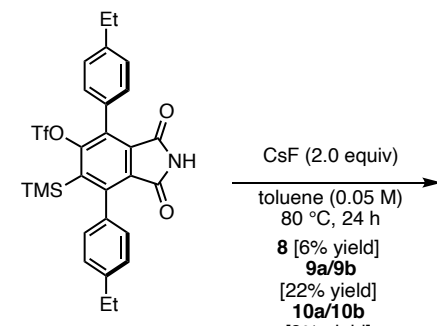

6 (1.0 equiv)

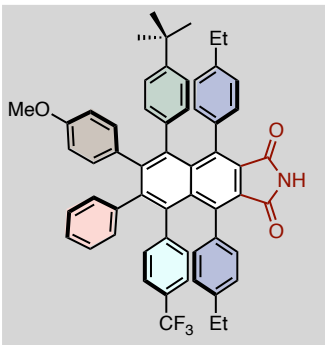

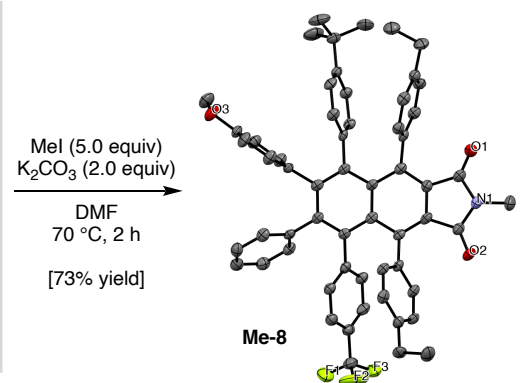

B

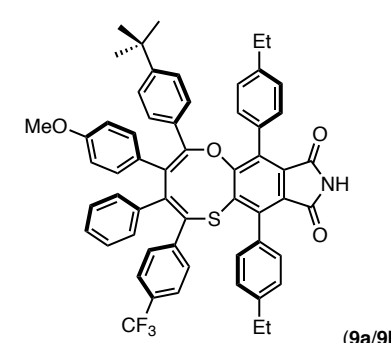

9a

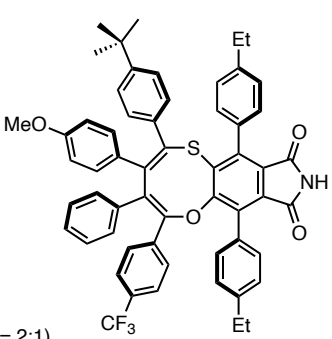

$9 b$

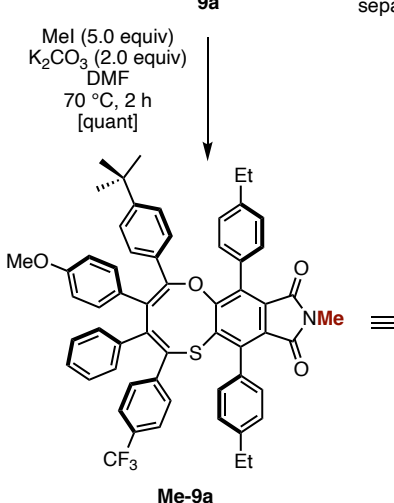

Me-9a

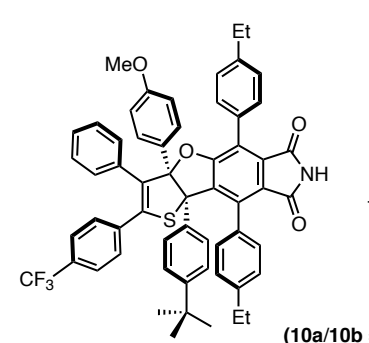

$10 \mathrm{a}$
$(10 \mathrm{a} / \mathbf{1 0 b}=5: 4$ or $4: 5)$

$$
\text { separable }
$$<smiles></smiles>

$10 \mathrm{~b}$ \begin{tabular}{l|l} 
1. $\mathrm{BBr}_{3}$ (20 equiv) & 3. Mel (5.0 equiv) \\
$\mathrm{CHCl}_{3}, 0^{\circ} \mathrm{C}$ to RT & 3. 5 .
\end{tabular}

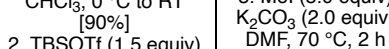
2.6-lutidine ( 3.0 equiv)
[quant]

$0{ }^{\circ} \mathrm{C}, 10 \mathrm{~min}[63 \%]$
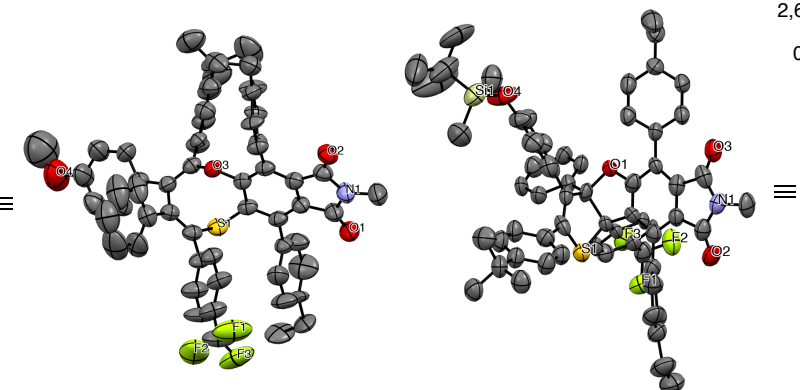

C
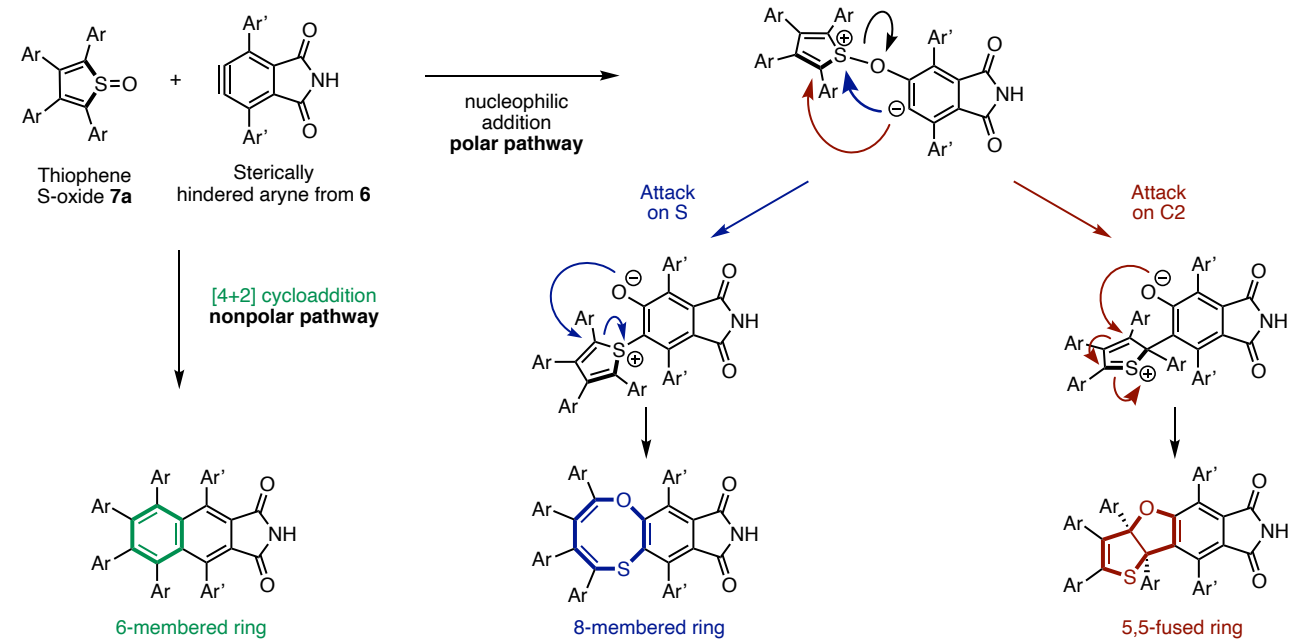

Synthesis of Decaarylanthracene (DAA).

To complete the synthesis of DAA, Hofmann rearrangement of $\mathbf{8}$, followed by hydrolysis, was conducted to provide hexaarylnaphtha- 
lyne precursor 11 as a mixture of regioisomers $(11 \mathrm{a} / \mathbf{1 1 b}=1: 1)$ in $78 \%$ combined yield (Scheme 3 ). Finally, treatment of this mixture with tert-butyl nitrite to give hexaarylnaphthalyne 12 , followed by reaction with thiophene $S$-oxide $7 \mathbf{b}$, produced decaarylanthracene (DAA: 13) as a mixture of regioisomers $(\mathbf{1 3 a} \mathbf{a} \mathbf{1 3} \mathbf{b}=1: 1)$ in $4 \%$ combined yield. These regioisomers were separable by preparative thin-layer chromatography.
Next, the absorption and fluorescence of the two isomers of DAA 13 were measured. ${ }^{16}$ The absorption and fluorescence of the parent decaphenylanthracene (DPA) was already reported by Pascal and coworkers, in which DPA has an absorption maximum at $429 \mathrm{~nm}$ and emission maxima at 486 and $512 \mathrm{~nm}$ (in cyclohexane). ${ }^{8} \mathrm{Com}$ pared with the synthesized DAAs 13, there are no large differences in photophysical properties between symmetrical DPA and highly unsymmetrical DAAs 13.

Scheme 3. Synthesis of decaarylanthracene (DAA).

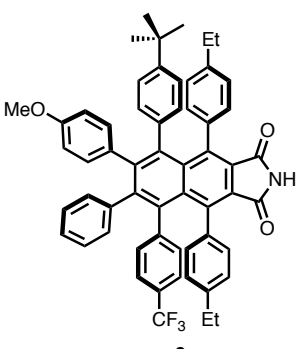

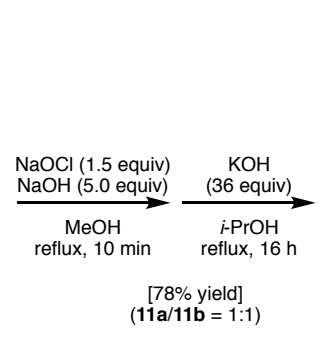

(1)

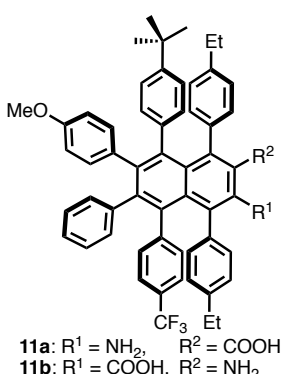

$\begin{array}{ll}11 a: R^{1}=\mathrm{NH}_{2}, & R^{2}=\mathrm{COOH} \\ \text { 11b: } \mathrm{R}^{1}=\mathrm{COOH}, & R^{2}=\mathrm{NH}_{2}\end{array}$

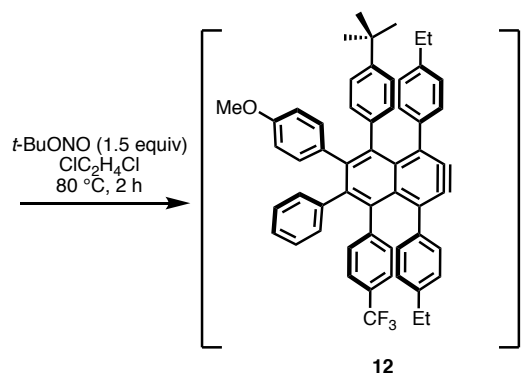

12
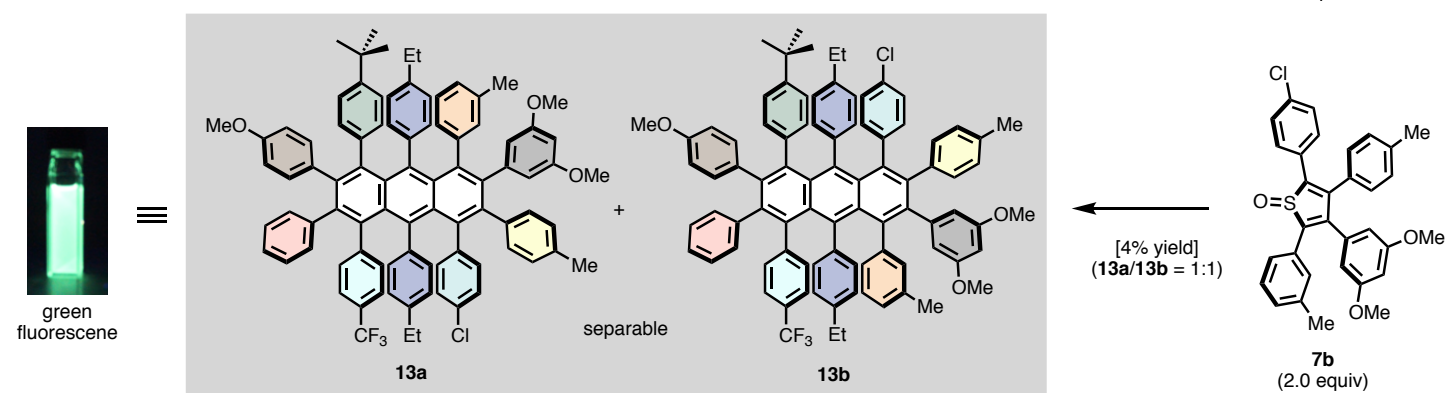

\section{-CONCLUSIONS}

In summary, a general synthetic method toward decaarylanthracene (DAA) has been developed by employing a [4+2] cycloaddition of tetraarylthiophene $S$-oxides with a series of multiply arylated arynes. The present study also shows the versatility of tetraarylthiophene $S$-oxides in [4+2] cycloaddition. Conveniently, all synthetic units $(6,7 \mathbf{a}$ and $7 \mathbf{b})$ are accessible from 3-methoxythiophene (1) as the starting material. Therefore, DAAs 12 can be synthesized by a combination of coupling and [4+2] cycloaddition of 3methoxythiophene (1). Moreover, different aryl groups could be installed onto the $\mathrm{C} 2$ and $\mathrm{C} 5$ positions of 3-methoxythiophene by $\mathrm{C}-\mathrm{H}$ arylation developed in our group, ${ }^{17}$ which would lead to the synthesis of double benzyne precursor B with two different aryl groups. Although the yield and regioselectivity in the [4+2] cycloaddition steps require improvement, this methodology, in principle, allows access to decaarylanthracenes with substituents that are all different. With the development of a new method that can synthesize previously unattainable molecular structures, the discovery of new functional materials can be expected.

\section{- ASSOCIATED CONTENT}

The Supporting Information is available free of charge.

Experimental procedures and spectroscopic data for compounds including ${ }^{1} \mathrm{H},{ }^{13} \mathrm{C}$ NMR spectra (PDF)

\section{- AUTHOR INFORMATION}

\section{Corresponding Author}

*junyamaguchi@waseda.jp

\section{ORCID}

Junichiro Yamaguchi: 0000-0002-3896-5882

\section{Notes}

No competing financial interests have been declared.

\section{- ACKNOWLEDGMENTS}

This work was supported by JSPS KAKENHI Grant Number JP19H02726 (to J.Y.). We thank Prof. Yasuhide Inokuma (Hokkaido University) for assistance with X-ray crystallography. The Materials Characterization Central Laboratory in Waseda University is acknowledged for the support of HRMS measurement.

\section{- REFERENCES}

(1) (a) Bendikov, M.; Wudl, F.; Perepichka, D. F. Tetrathiafulvalenes, Oligoacenenes, and Their Buckminsterfullerene Derivatives: The Brick and Mortar of Organic Electronics. Chem. Rev. 2004, 104, 4891-4946. (b) Anthony, J. E. Functionalized Acenes and Heteroacenes for Organic Electronics. Chem. Rev. 2006, 106, 5028-5048. (c) Anthony, J. E. The Larger Acenes: Versatile Organic Semiconductors. Angew. Chem., Int. Ed. 2008, 47, 452-483. (d) Wang, C.; 
Dong, H.; Hu, W.; Liu, Y.; Zhu, D. Semiconducting $\pi$-Conjugated Systems in Field-Effect Transistors: A Material Odyssey of Organic Electronics. Chem. Rev. 2012, 112, 2208-2267. (e) Ye, W.; Chi, C. Recent Highlights and Perspectives on Acene Based Molecules and Materials. Chem. Mater. 2014, 26, 4046-4056. (f) Lakshminarayana, A. N.; Ong, A.; Chi, C. Modification of Acenes for n-Channel OFET Materials. J. Mater. Chem. C2018, 6, 3551-3563. (g) Chen, M.; Yan, L.; Zhao, Y.; Murtaza, I.; Meng, H.; Huang, W. Anthracene-Based Semiconductors for Organic Field-Effect Transistors. J. Mater. Chem. C2018, 6, 7416-7444.

(2) (a) Shi, J.; Tang, C. W. Anthracene Derivatives for Stable BlueEmitting Organic Electroluminescence Devices. Appl. Phys. Lett. 2002, 80, 3201-3203. (b) Li, J.; Zhou, K.; Liu, J.; Zhen, Y.; Liu, L.; Zhang, J.; Dong, H.; Zhang, X.; Jiang, L.; Hu, W. Aromatic Extension at 2,6-Positions of Anthracene toward an Elegant Strategy for Organic Semiconductors with Efficient Charge Transport and Strong Solid State Emission. J. Am. Chem. Soc. 2017, 139, 1726117264. (c) Liu, J.; Zhang, H.; Dong, H.; Meng, L.; Jiang, L.; Jiang, L.; Wang, Y.; Yu, J.; Sun, Y.; Hu, W.; Heeger, A. J. High Mobility Emissive Organic Semiconductor. Nat. Commun. 2015, 6, 1003210039.

(3) Ito, K.; Suzuki, T.; Sakamoto, Y.; Kubota, D.; Inoue, Y.; Sato, F.; Tokito, S. Oligo(2,6-anthrylene)s: Acene-Oligomer Approach for Organic Field-Effect Transistors. Angew. Chem., Int. Ed. 2003, 42, 1159-1162.

(4) (a) Podzorov, V.; Sysoev, S. E.; Loginova, E.; Pudalov, V. M.; Gershenson, M. E., Single-crystal Organic Field Effect Transistors with the Hole Mobility $\sim 8 \mathrm{~cm}^{2} \mathrm{O} / \mathrm{Vs}$ Appl. Phys. Lett. 2003, 83, 3504-3506. (b) Sundar, V. C.; Zaumseil, J.; Podzorov, V.; Menard, E.; Willett, R. L.; Someya, T.; Gershenson, M. E.; Rogers, J. A. Elastomeric Transistor Stamps: Reversible Probing of Charge Transport in Organic Crystals. Science 2004, 303, 1644-1646. (c) Tang, X.; Hu, Y.; Jia, W.; Pan, R.; Deng, J.; Deng, J.; He, Z.; Xiong, Z. Intersystem Crossing and Triplet Fusion in Singlet-FissionDominated Rubrene-Based OLEDs Under High Bias Current. ACS Appl. Mater. Interfaces 2018, 10, 1948-1956.

(5) Duong, H. M.; Bendikov, M.; Steiger, D.; Zhang, Q.; Sonmez, G.; Yamada, J.; Wudl, F. Efficient Synthesis of a Novel, Twisted and Stable, Electroluminescent "Twistacene." Org. Lett. 2003, 5, 4433-4436.

(6) (a) Suzuki, S.; Yamaguchi, J. Synthesis of Fully Arylated (Hetero)arenes. Chem. Commun. 2017, 53, 1568-1582. (b) Asako, T.; Muto, K.; Yamaguchi, J. Synthesis of Fully Arylated (Hetero)arenes by Coupling Reaction. J. Synth. Org. Chem. Jpn. 2018, 76, 98-110.

(7) (a) Pascal, R. A., Jr. Twisted Acenes. Chem. Rev. 2006, 106, 4809 4819. (b) Wu, D.; Ge, H.; Liu, S. H.; Yin, J. Arynes in the Synthesis of Polycyclic Aromatic Hydrocarbons. RSC Adv. 2013, 3, 2272722738. (c) Dorel, R.; Echavarren, A. M. Strategies for the Synthesis of Higher Acenes. Eur. J. Org. Chem. 2017, 14-24. (d) Dyan, O. T.; Borodkin, G. I.; Zaikin, P. A. The Diels-Alder Reaction for the Synthesis of Polycyclic Aromatic Compounds. Eur. J. Org. Chem. 2019, 7271-7306.

(8) Qiao, X.; Padula, M. A.; Ho, D. M.; Vogelaar, N. J.; Schutt, C. E.; Pascal, R. A., Jr. Octaphenylnaphthalene and Decaphenylanthracene. J. Am. Chem. Soc. 1996, 118, 741-745.

(9) (a) Lu, J.; Ho, D. M.; Vogelaar, N. J.; Kraml, C. M.; Pascal, R. A., Jr. A Pentacene with a $144^{\circ}$ Twist. J. Am. Chen. Soc. 2004, 126, 11168-11169. (b) Lu, J.; Ho, D. M.; Vogelaar, N. J.; Kraml, C. M.; Bernhard, S.; Byrne, N.; Kim, L. R.; Pascal, R. A., Jr. Synthesis, Structure, and Resolution of Exceptionally Twisted Pentacenes. J. Am. Chem. Soc. 2006, 128, 17043-17050. (c) Clevenger, R. G.; Kumar, B.; Menuey, E. M.; Lee, G.-H.; Patterson, D.; Kilway, K. V. A Superior Synthesis of Longitudinally Twisted Acenes. Chem. Eur. J. 2018, 24, 243-250. (d) Clevenger, R. G.; Kumar, B.; Menuey, E. M.; Kilway, K. V. Synthesis and Structure of a Longitudinally Twisted Hexacene. Chem. Eur. J. 2018, 24,3113-3116. (e) Xiao, Y.; Mague, J. T.; Schmehl, R. H.; Haque, F. M.; Pascal, R. A.,
Jr. Dodecaphenyltetracene. Angew. Chem., Int. Ed. 2019, 58, 2831-2833.

(10) (a) Suzuki, S.; Segawa, Y.; Itami, K.; Yamaguchi, J. Synthesis and Characterization of Hexaarylbenzenes with Five or Six Different Substituents Enabled by Programmed Synthesis. Nat. Chem. 2015 7, 227-233. (b) Lungerich, D.; Reger, D.; Hölzel, H.; Riedel, R.; Martin, M. M. J. C.; Hampel, F.; Jux, N. A Strategy towards the Multigram Synthesis of Uncommon Hexaarylbenzenes. Angew. Chem., Int. Ed. 2016, 55, 5602-5605.

(11) (a) Asako, T.; Hayashi, W.; Amaike, K.; Suzuki, S.; Itami, K.; Muto K.; Yamaguchi, J. Synthesis of Multiply Arylated Pyridines. Tetrahedron 2017, 73, 3669-3676. (b) Suzuki, S.; Itami, K.; Yamaguchi, J. Synthesis of Octaaryl Naphthalenes and Anthracenes with Different Substituents. Angew. Chem., Int. Ed. 2017, 56, 1501015013. (c) Suzuki, S.; Asako, T.; Itami, K.; Yamaguchi, J. Modular Synthesis of Heptaarylindole. Org. Biomol. Chem. 2018, 16, 3771-3776. (d) Asako, T.; Suzuki, S.; Itami, K.; Muto, K.; Yamaguchi, J. Synthesis of a Heptaarylisoquinoline: Unusual Disconnection for Constructing Isoquinoline Frameworks. Chem. Lett. 2018, 47, 968-970. (e) Tanaka, S.; Asako, T.; Ota, E.; Yamaguchi, J. Synthesis of A Pentaarylcarbazole: Installation of Different Aryl Groups on Benzenoid Moiety. Chem. Lett. 2020, Advanced Publication. DOI: $10.1246 / \mathrm{cl} .200302$.

(12) (a) Hart, H.; Lai, C. Y.; Nwokogu, G.; Shamouilian, S.; Teuerstein, A.; Zlotogorski, C. Bisannelation of Arenes with Bisaryne Equivalents. J. Am. Chem. Soc. 1980, 102, 6649-6651. (b) Hart, H.; Ok, D. Synthesis of 1,5-Diamino-1,5-dihydrobenzo[1,2-d:4,5$d^{\prime}$ bistriazole (DABT) and Its Use as a 1,4-Benzadiyne Equivalent. J. Org. Chem. 1986, 51, 979-986. (c) Winling, A.; Russell, R. A. A Mild and Efficient Method for the Synthesis of Mixed Adducts of 1,4-Bis-Benzyne. J. Chem. Soc., Perkin Trans. 1 1998, 23, 39213923. (d) Schuster, I. I.; Craciun, L.; Ho, D. M.; Pascal, R. A., Jr. Synthesis of a Strained, Air-Sensitive, Polycyclic Aromatic Hydrocarbon by Means of a New 1,4-Benzadiyne Equivalent. Tetrahedron 2002, 58, 8875-8882. (e) Chen, Y. L.; Sun, J. Q.; Wei, X.; Wong, W.-Y.; Lee, A. W. M. Generation of Synthetic Equivalents of Benzdiynes From Benzobisoxadisiloles. J. Org. Chem. 2004, 69, 7190-7197. (f) Morton, G. E.; Barrett, A. G. M. 1,4-Difluoro-2,5Dimethoxybenzene as a Precursor for Iterative Double BenzyneFuran Diels-Alder Reactions. J. Org. Chem. 2005, 70, 3525-3529. (g) Hamura, T.; Arisawa, T.; Matsumoto, T.; Suzuki, K. TwoDirectional Annelation: Dual Benzyne Cycloadditions Starting from Bis(sulfonyloxy)diiodobenzene. Angew. Chem., Int. Ed. 2006, 45, 6842-6844. (h) Pei, B. J.; Chan, W. H.; Lee, A. W. M. Oxadisilole Fused Triptycene and Extended Triptycene: Precursors of Triptycyne and Extended Triptycyne. J. Org. Chem. 2010, 75, 7332-7337. (i) Abdelhamid, I. A.; Habib, O. M. A.; Butenschön, H. The First Benzo[1,2:4,5] dicyclobutenones and Their Tricarbonylchromium Complexes. Eur. J. Org. Chem. 2011, 4877-4884. (j) Alonso, J. M.; Díaz-Álvarez, A. E.; Criado, A.; Pérez D.; Peña, D.; Guitián, E. [16]Cloverphene: a Clover-Shaped cataCondensed Nanographene with Sixteen Fused Benzene Rings. Angew. Chem., Int. Ed. 2012, 51, 173-177. (k) Schuler, B.; Collazos, S.; Gross, L.; Meyer, G.; Pérez, D.; Guitián, E.; Peña, D. From Perylene to a 22-Ring Aromatic Hydrocarbon in One-Pot. Angew. Chem., Int. Ed. 2014, 53, 9004-9006. (1) Rodríguez-Lojo, D.; Pérez, D.; Peña, D.; Guitián, E. Large Phenyl-Substituted Acenes by Cycloaddition Reactions of the 2,6-Naphthodiyne Synthon. Chem. Commun. 2015, 51, 5418-5420. (m) Ikawa, T.; Masuda, S.; Takagi, A.; Akai, S. 1,3- and 1,4-Benzdiyne Equivalents for Regioselective Synthesis of Polycyclic Heterocycles. Chem. Sci. 2016, 7, 5206-5211. (n) Shi, J.; Li, Y.; Li, Y. Aryne Multifunctionalization with Benzdiyne and Benztriyne Equivalents. Chem. Soc. Rev. 2017, 46, 1707-1719. (o) Kitamura, T.; Gondo, K.; Oyamada, J. Hypervalent Iodine/Triflate Hybrid Benzdiyne Equivalents: Access to Controlled Synthesis of Polycyclic Aromatic Compounds. J. Am. Chem. Soc. 2017, 139, 8416-8419. 
(13) Yanagisawa, S.; Itami, K. Palladium/2,2'-bipyridyl $/ \mathrm{Ag}_{2} \mathrm{CO}_{3}$ Catalyst for $\mathrm{C}-\mathrm{H}$ Bond Arylation of Heteroarenes with Haloarenes. Teterahedron 2011, 67, 4425-4430.

(14) For details regarding screening conditions, see the Supporting Information.

(15) (a) Yoshida, S.; Yano, T.; Misawa, Y.; Sugimura, Y.; Igawa, K.; Shimizu, S.; Tomooka, K.; Hosoya, T. Direct Thioamination of Arynes via Reaction with Sulfilimines and Migratory $N$-Arylation. $J$. Am. Chem. Soc. 2015, 137, 14071-14074. (b) Matsuzawa, T.; Uchida, K.; Yoshida, S.; Hosoya, T. Synthesis of Diverse oArylthio-Substituted Diaryl Ethers by Direct Oxythiolation of Ar- ynes with Diaryl Sulfoxides Involving Migratory $O$-Arylation. Org. Lett. 2017, 19, 5521-5524.

(16) The measured absorption and fluorescence wavelength of DAAs 13 (in dichloromethane) are summarized, and the measured spectra are shown in the Supporting Information.

(17) (a) Yanagisawa, S.; Sudo, T.; Noyori, R.; Itami, K. Direct C-H Arylation of (Hetero)arenes with Aryl Iodides via Rhodium Catalysis. J. Am. Chem. Soc. 2006, 128, 11748-11749. (b) Yanagisawa, S.; Ueda, K.; Sekizawa, H.; Itami, K. Programmed Synthesis of Tetraarylthiophenes through Sequential C-H Arylation. J. Am. Chem. Soc. 2009, 131, 14622-14623. 